\title{
Assessment of the diversity of mental work in the context of the digitalization of the economy
}

\author{
A.F. Stepus ${ }^{1, *}$, E.Yu. Zlobina ${ }^{2}$, S.N. Firsova ${ }^{2}$, I.V. Matveeva ${ }^{2}$, and E.A. Domaratskaya ${ }^{2}$ \\ ${ }^{1}$ LLC "Corporation" Axion ", st. Maxim Gorky, 90, 426000 Izhevsk, Russia \\ ${ }^{2}$ Kalashnikov Izhevsk State Technical University, Studencheskaya st., 7, 426069 Izhevsk, Russia
}

\begin{abstract}
The article provides a detailed analysis of the developments of domestic scientists in the field of assessing the complexity of mental work. The directions of labor reduction are considered, the possibility of using this methodology in the development of modern methods for assessing the diversity of accumulated professions is given. The research of modern scientists in the field of digitalization, in terms of the emergence of threats to the stability of the economy, is considered. This is especially important given the fact that mental work of different categories is more significantly different from predominantly physical work of different categories, which requires taking into account in special units of changes in the complexity of mental work.
\end{abstract}

\section{Introduction}

In the context of the development of labor automation and the expansion of the digital economy's coverage of spheres of economic life, the issue of assessing predominantly mental work becomes more and more urgent, which in a new era of changes changes not only its content, but the professions themselves begin to change and increase their differentiation. Employers in the previous conditions did not betray such importance to the breadth and outlook of the professional knowledge of workers, even yesterday any manager valued only productivity and personal efficiency in subordinates, and now it is beginning to be appreciated by how many professions his staff own, the possibility of using the professions available to staff in changing market conditions and increasing new market requirements. The ability to work of personnel in our study is generally accepted to understand the diversity of professions. Assessment of the ability to work for each profession should take into account the level of qualifications, since it is precisely complex mental work in terms of the level of qualifications that already differs more significantly in comparison with the same predominantly physical labor of the past. Assessment of the complexity of mental work is important in addition to the variety of professions and for a number of aspects of further application: the ratio of the degree of intensity of one employee compared to another, checking the compliance of the qualification level of the employee, identifying potential employees for optimization, checking the compliance of the results of mental work in comparison with the remuneration paid to the employee for work.

\footnotetext{
* Corresponding author: stepus19811@mail.ru
} 
In the traditional sense, the laws of economic reality, completely different in purpose, were universally confirmed, from which the personnel and the employer proceed. The staff proceeds from the law of universalization of people's knowledge, following the even more universal law of the noosphere of Vernadsky [1], and strives to increase their professional diversity - the ability to work. The employer proceeded from a constant increase in the efficiency of personnel, since this reduction in labor costs and an increase in results is a direct consequence of another law - the law of differentiation of production processes. The revealed regularity is reduced to the very essence of the capitalist formation, which arose due to the action of cooperation and the division of labor, so the law of differentiation of production processes divides labor in order to divide it into the smallest transitions and operations devoid of the complexity of the labor process. This division leads to the concentration of human efforts and the improvement of each such transition or operation to such a minimum duration that time is naturally saved, and, consequently, efficiency increases. The way of human cognition according to the law of universalization of people's knowledge is such that with each such improved operation or transition, the employee makes an increase in the complexity and intensity (speed) of his labor, moving the object of his further cognition to other areas, changing the application of his labor, therefore, his ability to work increases. This opposite direction of the two laws created a system of interaction between the employee and the employer, leading to the natural progress of humanity as a whole. In the modern world, this clash of two laws no longer becomes so relevant when labor becomes predominantly mental, the digitalization and automation of labor is growing, the replacement of a person by a machine occurs not only in predominantly physical labor, but also in predominantly mental labor. However, despite the development of artificial intelligence, which is intended to replace mental work, the features of the practice of application and modern development are such that it is not possible to replace the role of a person in the full sense of the word. So with the development of technology and its capabilities, the old professions of a person simply expand and are replaced by new professions, through the possession of which it is possible to further develop and maintain new forms of division and cooperation of labor between man and machine. Consequently, the diverse experience of scientists, both modern and scientists of the past, both domestic and foreign, will always be relevant, who contributed to the development of assessing the complexity of labor as a basis for assessing the diversity of human mental activity in new conditions.

This study, in its subject of human mental activity, is considered in the works of such scientists as: S.G. Rosenthal, A.I. Safina, [2], E.A. Romanov, V.I. Pavlova, A.N. Romanova [3], O. M. Perminova, G.A. Lobanova, R.V. Faizullin, B.I. Goldfarb, E.G. Krylov, N.A. Barmina, L. Vasilevsky, G.E. Kalinkina, N.G. Sokolova, D.M. Hajikurbanov, K.V. Pavlov, V.E. Lyalin, T.A. Berkutova [4-8].

\section{Methods for assessing the diversity of mental work}

The essence of the considered process of interaction of the two previously considered laws is to replace the duration of the labor process with an increase in its intensity (complexity); indeed, practice confirms that with each subsequent repetition of the same operation, a person does it faster, due to dexterity and skill. What is contained in this skill and skill, if not the ability of a person to reduce the duration by reducing transitions or eliminating unnecessary movements and actions, the ability to gradually separate and improve in a similar way already more complex operations. This pattern of human evolution was noted by Karl Marx. In his work "Critique of the Gotha Program" he wrote one of the primary theses of the assessment of labor activity, which significantly clarifies the concept of "measure of labor". Thus Karl Marx writes: "The right of producers is proportional to the 
labor delivered to them; equality consists in the fact that the measurement is made by an equal measure - labor ... and labor, in order for it to serve as a measure, must be defined in terms of duration or intensity, otherwise it would cease to be a measure "[9]. The union "or" contains the very process of replacing the duration of labor with its intensity or complexity. The concept of "measure of labor" was introduced into the circulation of scientific political economy by K. Marx.

The practice of implementing these aspects consisted in the dispute between various scientists who were engaged in labor reduction and intensity assessment, which continued after Karl Marx. Reduction of Labor from the Position of the National Economic Reproduction Cycle V. Pozdnyakov, P.S. Mstislavsky. These views were largely shared by Academician S.G. Strumilin. However, an interesting hypothesis is put forward by one of the researchers of this scientific direction - E. Varga, according to his opinions, all personnel, regardless of qualifications, give an equal amount of labor during their life, but the time spent on training qualified personnel leads to more intensive work, therefore appropriate factors should be applied. So, if unskilled personnel work from 16 to 48 years on average 32 years, then, taking into account the time spent on training (within 4 years), a qualified employee will work from 20 to 48 years - on average 28 years. From these calculations it follows that qualified personnel (with training in 4 years) should give to society $1 / 8(=32 / 28=16 / 14=1$ whole $1 / 8)$ more labor during their working life during their working life. This concept reflects the interaction and transition of one category of "duration" (number of years of work) to another category of "intensity" (characteristics of accumulated learning, time spent on learning), so the more a person learns, the more intensively he works and works with a shorter duration, as opposed to if he did not study and would work with less intensity for a longer duration. As a result, the put forward idea that personnel give an equal amount of labor during their life, taking into account the level of their quality, is confirmed by this researcher. For this reason, it is possible to equate labor costs when creating the same utility as the product of the complexity of labor and working time for different skill levels.

Reduction of labor based on taking into account the social costs of educating a skilled labor force R. Hilferding, G. Deutsch and O. Bauer, F. M. Volkov, V. F. Mayer, E. I. Kapustin, M. V. Ioffe. Research by a group of scientists in this scientific direction also equates the labor costs of complex and simple labor in the same type of activity. The broadest methodological base confirming the equality of labor costs of complex and simple labor is the approach to reduction from the standpoint of social labor costs for the education of qualified personnel. This aspect will serve as the basis for the methodology for assessing the measure of labor.

However, all methods of labor reduction, even within the framework of one direction, received different reduction coefficients for the same labor, the reason for which in the absence of a single measure, a unit of labor measurement, but they carried out numerous justifications for the equality of labor costs of complex and simple labor, which is the basis for derivation of the labor unit of measurement - tred. In Soviet times, threads were analyzed by Academician S.G. Strumilin [10]. This unit of measurement of mental labor, contained the following functional, revealing the economic essence of precisely the complexity of labor (formula 1).

$$
q i=f \frac{T \text { thinking } \square T \text { working }}{T \text { working }}
$$

Where $\mathrm{q}_{\mathrm{i}}$ - is the labor unit of measure (thread); Tthinking - time spent on thinking about the labor process; Tworking - time directly spent on the labor process.

Many can reasonably assert that the time for thinking for personnel with different 
mental abilities is different, as well as the time for the direct process of labor, depending on the development of the physical abilities of the personnel, is different, but the measure is different because it is based on a standard. The standard of length of one meter does not assert that all people should have a step exactly one meter, but having become a measure of length, they live their own separate life. Partial inconsistencies with individual individuals do not prevent the same individuals from using this measure of length to measure the size of a site, a room and a diverse number of objects, similarly, "tred" serves as a measure of the complexity of labor. We cited the opinions of a number of researchers S.G. Strumilin, E. Varg, R. Hilferding, G. Deutsch, who argued about the unity of labor costs of complex and simple labor about their equality, both directly and indirectly, resorting to the equality of the results of complex and simple labor. Consideration of their importance for identifying the methodology of equality of labor costs (longer duration and less intensity) of simple labor with labor costs (shorter duration and greater intensity) of complex labor, which can be expressed mathematically (formula 2):

$$
\text { T labor costs } p 1=T \text { labor costs } p 2, \text { Tred } p 1 * T E \text { pl }=\text { Tred } p 2 * T E p 2
$$

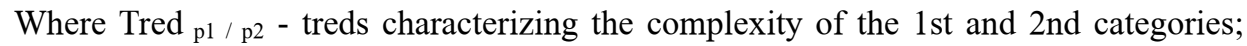
$\mathrm{TE}_{\mathrm{p} 1 / \mathrm{p} 2}$ - the labor intensity of the same work performed by personnel of the 1 st and $2 \mathrm{nd}$ categories, respectively.

Following this logic, you can come to the threads of the corresponding categories knowing the difference in labor intensity for the same work performed by personnel engaged mainly in mental work of different skill levels and conclude according to formula 3 that:

$$
T E p 1 \square T E p 2, K p 2=\frac{T E p 1}{T E p 2}, \operatorname{Tred} 2=K p 2 * \operatorname{Tred} p 1
$$

Where $\mathrm{K}_{\mathrm{p} 2}$ - is the growth factor of the 2 nd category tred compared to the 1 st category tred.

The mathematical justification consists in the following conclusions (formula 4):

$$
\text { If } K p 2=\frac{T E p 1}{T E p 2} \text { and } \operatorname{Tred} 2=K p 2 * \operatorname{Tred} p 1 \text {,then Tpedp } 2=\operatorname{Tpe\partial p} 1 \times \frac{T E p 1}{T E p 2}
$$

Based on these conclusions, it will be possible to develop a unit for measuring the complexity of mental work, which will measure how mental work.

\section{Practical development of "tred" - units of measurement of mental labor and the prospects for its application}

In modern socio-economic practice, the concept of "tred" is not fixed, but it is ubiquitously embedded in the system of social relations, in particular in the rationing of labor and the definition of labor intensity, which decreases with an increase in the qualifications of personnel, that is, in fact, the previously identified correspondence of labor costs of different complexity. So the normalized time of a less qualified specialist needs to be significantly more than the normalized time of a highly qualified specialist, although the labor costs necessary for the implementation of the desired labor process must be constant, that is, there must be one more value that takes into account the qualitative aspect of labor costs. The tred is contained in the standardized time, and when it is compared for various categories of personnel according to the level of complexity of their work, exactly the same 
values should be obtained that will be the basis of the methodological substantiation of the tred. If the hypothesis stated earlier is correct, then, to obtain the corresponding growth factors from the inconsistency of labor intensity for the same types of work for personnel with different categories of labor complexity, and their application in relation to treds of a lower category, you can obtain subsequent values of treds of a higher category. Below is an analysis of the time standards for process engineers of various categories performing work of various levels of complexity of work, depending on the complexity of the part.

Table 1. An example of calculating and defining threads by specialists

\begin{tabular}{|c|c|c|c|c|c|c|c|c|c|c|c|}
\hline \multirow{2}{*}{\begin{tabular}{|c|} 
Type of \\
technological \\
process \\
developed by the \\
technologist \\
\end{tabular}} & \multirow{2}{*}{$\begin{array}{l}\text { Detail } \\
\text { complexity } \\
\text { group }\end{array}$} & \multirow{2}{*}{$\begin{array}{c}\begin{array}{c}\text { Techni- } \\
\text { cian }\end{array} \\
\text { hours } \\
\end{array}$} & \multicolumn{2}{|c|}{$\begin{array}{c}\text { Senior } \\
\text { Techni-cian- } \\
\text { Techno-logist }\end{array}$} & \multicolumn{2}{|c|}{$\begin{array}{c}\text { Engineer } \\
\text { techno-logist }\end{array}$} & \multicolumn{2}{|c|}{$\begin{array}{c}\text { Process } \\
\text { Engineer } 3 \\
\text { Category }\end{array}$} & \multicolumn{2}{|c|}{$\begin{array}{c}\text { Process } \\
\text { Engineer } 2 \\
\text { Category }\end{array}$} & \multirow{2}{*}{$\begin{array}{c}\text { Process } \\
\text { Engineer1 } \\
\text { Category } \\
\text { hours } \\
\end{array}$} \\
\hline & & & hours & K 8 & hours & K 9 & hours & K10 & hours & K11 & \\
\hline \multirow{5}{*}{$\begin{array}{c}\text { For protective } \\
\text { and decorative } \\
\text { protective } \\
\text { coatings }\end{array}$} & Up to 15 & 2,5 & 2,3 & 1,09 & 2,1 & 1,10 & 2 & 1,05 & 1,7 & 1,18 & \\
\hline & Up to 25 & 3,3 & 3 & 1,10 & 2,7 & 1,11 & 2,5 & 1,08 & 2,2 & 1,14 & \\
\hline & Up to 35 & 5,2 & 4,7 & 1,11 & 4,3 & 1,09 & 4 & 1,08 & 3,5 & 1,14 & 3,3 \\
\hline & Up to 45 & & 6,5 & & 6 & 1,08 & 5,5 & 1,09 & 4,8 & 1,15 & 4,5 \\
\hline & Up to 60 & & & & & & 7,2 & & 6,3 & 1,14 & 6,3 \\
\hline \multicolumn{2}{|c|}{ Average odds } & & & 1,10 & & 1,10 & & 1,07 & & 1,15 & \\
\hline \multicolumn{2}{|c|}{ Difficulty level of labor } & 7 & & & \multicolumn{2}{|c|}{9} & \multicolumn{2}{|c|}{10} & \multicolumn{2}{|c|}{11} & 12 \\
\hline \multicolumn{2}{|c|}{ Treds } & 2,4 & \multicolumn{2}{|c|}{2,6346716} & \multicolumn{2}{|c|}{2,88675} & \multicolumn{2}{|c|}{3,1003013} & \multicolumn{2}{|c|}{3,5618629} & 3,712972 \\
\hline
\end{tabular}

These average values of growth factors and threads (Table 1) obtained with their help can be summarized in a pivot table (Table 2), to derive the total values for the entire set of standards, justification based on time observations and developed at a particular enterprise time standards for development of technological processes and design of technological equipment.

Table 2. Summary analysis of average growth rates and treds

\begin{tabular}{|c|c|c|c|c|c|c|c|c|c|c|}
\hline \multirow[t]{2}{*}{$\begin{array}{l}\text { Time } \\
\text { standard } \\
\text { card } \\
\text { number }\end{array}$} & \multirow[t]{2}{*}{\begin{tabular}{|c|}
$\begin{array}{c}\text { Technician- } \\
\text { technologist } \\
\text { (7th grade) }\end{array}$ \\
treds \\
\end{tabular}} & \multicolumn{2}{|c|}{$\begin{array}{c}\text { Senior } \\
\text { technician- } \\
\text { technologist } \\
\text { (8th grade) }\end{array}$} & \multicolumn{2}{|c|}{$\begin{array}{c}\text { Process } \\
\text { engineer } \\
\text { without } \\
\text { category (9th } \\
\text { grade) }\end{array}$} & \multicolumn{2}{|c|}{$\begin{array}{l}\text { Technological } \\
\text { engineer of the } \\
\text { 3rd category } \\
\text { (10th grade) }\end{array}$} & \multicolumn{2}{|c|}{$\begin{array}{l}\text { Technological } \\
\text { engineer of the } \\
\text { 2rd category } \\
\text { (11th grade) }\end{array}$} & \multirow[t]{2}{*}{\begin{tabular}{|c|} 
Technologica \\
1 engineer of \\
the $1 \mathrm{rd}$ \\
category \\
$(12$ th grade $)$ \\
treds
\end{tabular}} \\
\hline & & treds & K 8 & treds & K 9 & treds & K 10 & treds & K 11 & \\
\hline \multirow{2}{*}{1} & 2,4 & 2,6347 & 1,10 & 2,887 & 1,10 & 3,1003 & 1,07 & 3,5619 & 1,15 & 3,713 \\
\hline & 2,4 & 2,6205 & 1,09 & 2,919 & 1,11 & 3,1315 & 1,07 & 3,8279 & 1,22 & 4,077 \\
\hline \multirow{2}{*}{2} & 2,4 & 2,6391 & 1,10 & 2,885 & 1,09 & 3,1003 & 1,07 & 3,5889 & 1,16 & 3,773 \\
\hline & 2,4 & 2,6308 & 1,10 & 2,873 & 1,09 & 3,0841 & 1,07 & 3,5513 & 1,15 & 3,738 \\
\hline \multirow{2}{*}{3} & 2,4 & 2,6535 & 1,11 & 2,892 & 1,09 & 3,1113 & 1,08 & 3,6519 & 1,17 & 3,9 \\
\hline & 2,4 & 2,5942 & 1,08 & 2,875 & 1,11 & 3,0888 & 1,07 & 3,5697 & 1,16 & 3,828 \\
\hline \multirow{3}{*}{4} & 2,4 & 2,6489 & 1,10 & 2,883 & \begin{tabular}{l|l|}
1,09 \\
\end{tabular} & 3,1032 & 1,08 & 3,5541 & 1,15 & 3,745 \\
\hline & 2,4 & 2,6119 & 1,09 & 2,864 & 1,10 & 3,0657 & 1,07 & 3,5327 & 1,15 & 3,767 \\
\hline & 2,4 & 2,6168 & 1,09 & 2,858 & 1,09 & 3,0665 & 1,07 & 3,5161 & 1,15 & 3,724 \\
\hline \multirow{2}{*}{5} & 2,4 & 2,6048 & 1,09 & 2,881 & 1,11 & 3,0766 & 1,07 & 3,5839 & \begin{tabular}{ll|}
1,16 \\
\end{tabular} & 3,818 \\
\hline & 2,4 & 2,6161 & 1,09 & 2,889 & 1,10 & 3,0756 & 1,06 & 3,6002 & \begin{tabular}{l|}
1,17 \\
\end{tabular} & 3,839 \\
\hline \multirow{4}{*}{6} & 2,4 & 2,647 & 1,10 & 2,887 & 1,09 & 3,1111 & 1,08 & 3,5836 & 1,15 & 3,785 \\
\hline & 2,4 & 2,6009 & 1,08 & 2,949 & 1,13 & 3,1202 & 1,06 & 3,8902 & 1,25 & 4,114 \\
\hline & 2,4 & 2,6087 & 1,09 & 2,956 & 1,13 & 3,1169 & 1,05 & 3,8121 & 1,22 & 4,123 \\
\hline & 2,4 & 2,5942 & 1,08 & 2,936 & 1,13 & 3,116 & 1,06 & 3,8046 & 1,22 & 4,096 \\
\hline \multirow[b]{2}{*}{7} & 2,4 & 2,6383 & 1,10 & 2,861 & 1,08 & 3,1257 & 1,09 & 3,5571 & 1,14 & 3,739 \\
\hline & 2,4 & 2,6245 & $|1,09|$ & 2,864 & 1,09 & 3,0897 & 1,08 & 3,5448 & 1,15 & 3,731 \\
\hline
\end{tabular}


Table 2. Continued

\begin{tabular}{|c|c|c|c|c|c|c|c|c|c|c|}
\hline \multirow{2}{*}{8} & 2,4 & 2,6288 & 1,10 & 2,864 & 1,09 & 3,0352 & 1,06 & 3,3481 & 1,10 & 3,618 \\
\hline & 2,4 & 2,6549 & 1,11 & 2,971 & 1,12 & 3,3023 & 1,11 & 4,0459 & 1,23 & 4,346 \\
\hline \multirow{2}{*}{9} & 2,4 & 2,6256 & 1,09 & 2,907 & 1,11 & 3,0338 & 1,04 & 3,5859 & 1,18 & 3,983 \\
\hline & 2,4 & 2,585 & 1,08 & 2,933 & 1,13 & 3,0939 & 1,05 & 3,7955 & 1,23 & 4,098 \\
\hline \multirow{2}{*}{10} & 2,4 & 2,6718 & 1,11 & 2,958 & 1,11 & 3,0587 & 1,03 & 3,6143 & 1,18 & 3,916 \\
\hline & 2,4 & 2,5999 & 1,08 & 2,954 & 1,14 & 3,1117 & 1,05 & 3,8034 & 1,22 & 4,107 \\
\hline \multirow{2}{*}{11} & 2,4 & 2,5967 & 1,08 & 2,942 & 1,13 & 3,1069 & 1,06 & 3,8036 & 1,22 & 4,107 \\
\hline & 2,4 & 2,6222 & 1,09 & 2,939 & 1,12 & 3,1451 & 1,07 & 3,8168 & 1,21 & 4,123 \\
\hline \multirow{2}{*}{12} & 2,4 & 2,6335 & 1,10 & 2,875 & 1,09 & 3,1109 & 1,08 & 3,5486 & 1,14 & 3,744 \\
\hline & 2,4 & 2,6292 & 1,10 & 2,874 & 1,09 & 3,0873 & 1,07 & 3,5826 & 1,16 & 3,784 \\
\hline 13 & 2,4 & 2,6221 & 1,09 & 3,109 & 1,19 & 3,5672 & 1,15 & 3,7741 & 1,06 & 4,003 \\
\hline 14 & 2,4 & 2,6386 & 1,10 & 3,129 & 1,19 & 3,5766 & 1,14 & 3,7724 & 1,05 & 4,049 \\
\hline \multirow{3}{*}{15} & 2,4 & 2,6114 & 1,09 & 3,071 & 1,18 & 3,5603 & 1,16 & 3,7224 & 1,05 & 3,959 \\
\hline & 2,4 & 2,6331 & 1,10 & 3,129 & 1,19 & 3,5904 & 1,15 & 3,7816 & 1,05 & 4,02 \\
\hline & 2,4 & 2,611 & 1,09 & 3,06 & 1,17 & 3,5524 & 1,16 & 3,7659 & 1,06 & 3,947 \\
\hline \multirow{3}{*}{16} & 2,4 & 2,6497 & 1,10 & 3,136 & 1,18 & 3,5842 & 1,14 & 3,7906 & 1,06 & 4,023 \\
\hline & 2,4 & 2,6516 & 1,10 & 3,102 & 1,17 & 3,574 & 1,15 & 3,7724 & 1,06 & 3,993 \\
\hline & 2,4 & 2,642 & 1,10 & 3,089 & 1,17 & 3,5543 & 1,15 & 3,7948 & 1,07 & 4,071 \\
\hline \multirow{3}{*}{17} & 2,4 & 2,635 & 1,10 & 3,122 & 1,18 & 3,5831 & 1,15 & 3,7575 & 1,05 & 4,007 \\
\hline & 2,4 & 2,635 & 1,10 & 3,122 & 1,18 & 3,5831 & 1,15 & 3,7575 & 1,05 & 4,007 \\
\hline & 2,4 & 2,635 & 1,10 & 3,122 & 1,18 & 3,5831 & 1,15 & 3,7575 & 1,05 & 4,007 \\
\hline \multirow{2}{*}{18} & 2,4 & 2,6331 & 1,10 & 3,099 & 1,18 & 3,5616 & 1,15 & 3,76 & 1,06 & 3,991 \\
\hline & 2,4 & 2,635 & 1,10 & 3,122 & 1,18 & 3,5831 & 1,15 & 3,7575 & 1,05 & 4,007 \\
\hline \multirow{2}{*}{19} & 2,4 & 2,6059 & 1,09 & 2,943 & 1,13 & 3,0966 & 1,05 & 3,8062 & 1,23 & 4,137 \\
\hline & 2,4 & 2,5978 & 1,08 & 2,961 & 1,14 & 3,1115 & 1,05 & 3,8361 & 1,23 & 4,219 \\
\hline Treds & 2,4 & 2,6254 & & 2,969 & & 3,2484 & & 3,6972 & & 3,947 \\
\hline
\end{tabular}

After analyzing the dependence of the table. 2, the following formula was chosen 5 for calculating treds, depending on the qualification category:

$$
\text { Tred }=0,943 * 1,134^{\text {grade }}
$$

The values of the received treds practically coincide from 1 to 18 categories for workers, specialists and managers of an industrial enterprise and cover all professions and categories of production personnel, where the director of the enterprise has the 18th category, and the apprentice of a worker who has just been hired at the plant has 1 -th category. An assessment of the diversity of professions or work ability can be carried out by summing such treds, taking into account the achieved level of qualifications for all professions of the employee. This criterion for assessing the competitiveness of personnel is becoming more and more relevant in the context of the digitalization of the economy.

\section{Conclusions}

1. In modern conditions of building a new labor economy, it becomes necessary to develop a labor methodology, taking into account the current state of digitalization practice, as stated by many scientists Yu.G. Odegov, V.V. Pavlova [11], R.P. Kolosova, T.O. Razumova, M.V. Artamonov [12], V.N. Bobkov, N.A. Volgin, E.I. Kurilchenko [13], I. D. Matskulyak, V.D. Kuligin, D.I. Matskulyak, N.Z.Nagdaliev [14]. We propose to create a methodological basis for labor assessment, based on domestic developments in this area.

2. This assessment system allows you to calculate and compare the working capacity of personnel, take this into account when hiring on the labor market, in the processes of 
personnel optimization, identifying the most flexible employees in terms of professions and leaving them at the enterprise in the first place, with the aim of the subsequent more stable functioning of the enterprise.

3. Tred as a category for assessing complexity should be taken into account in the new conditions of digitalization when developing standards for the number and standards of time, labor costs of personnel engaged mainly in mental work in all professions of a new era of economic development.

4. The applied methods of assessing and calculating the complexity of mental work also make it possible to assess the intensity or speed of work of each employee, to build on it individually qualification improvement, as well as to link the amount of remuneration for an increase in qualifications to his personal achievements of the growth of the complexity of personal labor. This is all about the use of "tred" in microeconomics.

5. In a broader macroeconomic and regional sense, "tred" as a category of labor units of measurement is becoming an urgent basis for building a platform for converting the ruble as the currency of the new Eurasian economic zone led by Russia. The collapse of the world Breton Woods dollar system, taking place over the past few years, provides a historic chance to build its own sovereign economic zone with its own currency. By the way, at the dawn of the development of the Soviet state, approximately 100 years ago, V.I. Lenin [15], proposing to introduce for workers "certificates" in which to take into account the work of each to provide him with the results of labor in the form of goods. A little later I.V. Stalin in his undoubtedly scientific work [16] substantiated the problems that needed to be solved for the implementation of this thesis. In our current state, with the growth of social threats, the threat of hunger and the need for social and political stability on the part of the ruling elites, the time itself requires the introduction of some social cards for the poorer strata of the population, to provide them with consumer goods and services of a social minimum, which requires precisely the labor assessment and accounting of such benefits, from the point of view of the return of mental labor in the new conditions of digitalization, to exchange this labor assessment for goods and services directly, bypassing hyperinflation and the impact of exchange rates. The trade would be a scientifically based, factual and practical instrument for the stability of the new Eurasian economic zone in an unstable world.

\section{References}

1. V.I. Vernadsky. About science. 1. Scientific knowledge. Scientific creativity. Scientific thought. Part 3. Scientific thought as a planetary phenomenon (1997)

2. S.G. Rosenthal, A.I. Safina, Scientific Notes of Kazan University, Natural Sciences Series, 157, 3 (2015)

3. E.A. Romanov, V.I. Pavlova, A.N. Romanova, Vestnik SURGU, 37 (2010)

4. V.I. Goldfarb, E.G. Krylov, O.M. Perminova, N.A. Barmina, L. Vasiliev, Aspects of Teaching Future Mechanical Engineers on Bachelor of Science Programs at Technical Universities (2018)

5. K.V. Pavlov, O. M. Perminova, V.E. Lyalin, G.E. Kalinkina, T.A. Berkutova, 24th International Vibration Engineering Conference (2016).

6. O.M. Perminova, G.A. Lobanova, Acta Logistica, 1(5) (2018)

7. O. M. Perminova, G.A. Lobanova, R.V. Faizullin, Acta Logistica, 2 (2019)

8. G.E. Kalinkina, N.G. Sokolova, D.M. Hajikurbanov, O.M. Perminova, "23rd International Conference on Vibration Engineering" (2016)

9. K. Marx, Criticism of the Gotha Program (1977) 
10. S.G. Strumilin, Selected works in 5 volumes (1965)

11. Yu.G. Odegov, V.V. Pavlova Living standard of the population of Russian regions, 4 (2017)

12. R.P. Kolosova, T.O. Razumova, M.V. Artamonova, Moscow University Bulletin Ser. 6, 3 (2019)

13. V.N. Bobkov, N.A. Volgin, E.I. Kurilchenko, Living standards of the population of Russian regions, 2 (2014)

14. I.D. Matskulyak, V.D. Kuligin, D.I. Matskulyak, N.Z. Nagdaliev, University Bulletin, 9 (2020)

15. V.I. Lenin, Complete Works: State and Revolution. (1980)

16. I. V. Stalin Economic problems of socialism in the USSR (1952) 